\title{
Examination of the Level of Participation of Secondary School Students in Extracurricular Sports Activities [Burdur Example]
}

\author{
Mehmet ŞAHIN \\ 'European University of Lefke TRNC, Northern Cyprus \\ Email:cumsahin@hotmail.com
}

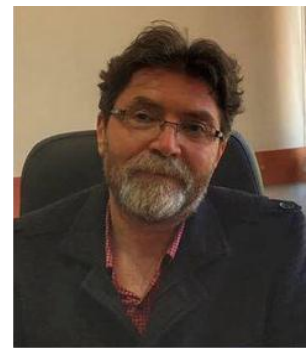

\begin{abstract}
This research aims to determine the level of participation of secondary school students in Burdur in extracurricular sports activities and the issues they experience. 247 secondary school students in Burdur participated in this research. A survey composed of a total of 19 questions developed by Selçuk (2006) was used. In conclusion; when taking into account the factor of which grade secondary school students are in, it has been determined that football and volleyball are the most preferred branches of sport in all grades, and that there are statistically no significant differences between extracurricular sports activities according to which grade students are in. It has been determined that secondary school students who have participated in the study statistically present no significant differences in their extracurricular sports activities according to the profession of their fathers. It has been determined that the support shown by the families of students participating in the study in terms of their engagement in sports, statistically demonstrates no significant difference according to the number of people in the family. It has been determined that the support shown by the families of students participating in the study in terms of their engagement in sports, statistically demonstrates no significant difference according to the profession of their mothers. It has been observed that the rate of support given for engaging in sport by families of participants whose mothers are white collar workers are higher than other families. It has been determined that statistically, there are significant differences between extracurricular sports activities secondary school students engage in, according to their genders. It was found that the changes in academic status during the which secondary school students participate in extracurricular sports competitions statistically demonstrates no significant difference according to their genders.
\end{abstract}

Keywords: Secondary school students, Extracurricular, Sports activities.

Citation | Mehmet ŞAHIN (2018). Examination of the Level of Participation of Secondary School Students in Extracurricular Sports Activities $\ulcorner$ Burdur Example $\rceil$. Asian Journal of Education and Training, 4(2): $171-176$.

History:

Received: 2 April 2018

Revised: 16 April 2018

Accepted: 20 April 2018

Published: 23 April 2018

Licensed: This work is licensed under a Creative Commons

Attribution 3.0 License (cc) E E

Publisher: Asian Online Journal Publishing Group
Funding: This study received no specific financial support.

Competing Interests: The author declares that there are no conflicts of interests regarding the publication of this paper.

Transparency: The author confirms that the manuscript is an honest, accurate, and transparent account of the study was reported; that no vital features of the study have been omitted; and that any discrepancies from the study as planned have been explained.

Ethical: This study follows all ethical practices during writing.

\section{Contents}

1. Introduction

2. Method 


\section{Introduction}

The term education is defined as the process during which changes are implemented on the terminal behavior of an individual by means of his/her own experiences and in an intentional manner (Ertürk, 1975). Education is the process which brings forth changes in behavior or creates certain behavior; in fact, it mostly does both at the same time. Behavior to be generated are not random, they must be desired, or, in other words, target-specific, and the development of these will be ensured with planned activities. Terminal behavior and educational activities to be used in creating these, the evaluation of the degree of effectiveness of these activities, and in accordance with the results obtained from the evaluation, the planning of corrective measures and implementations to remedy deficiencies and principles in relation to these are explained in education programs. Extracurricular sports activities are "planned, programmed, regular activities which take place in schools, outside of class time, in accordance with educational objectives, in line with students' interests and needs, for their physical and spiritual development, with the knowledge of school management and under the guidance of physical education teachers" (Binbaşığlu, 2000). The secondary school period, a transitional stage from childhood to adulthood, is one during which students' physical, spiritual, social and cultural development is at its highest level. Students need an education which will meet all their needs during this period. Developing students with their physical, mental, spiritual, social and cultural aspects as a whole, is the general objective of education. Seeing as physical education is considered to be an inseparable part of general education; general education and physical education must share the same objectives and there must not be any discrepancies between objectives (Cömert, 1999). It is impossible for students to obtain the sufficient development and education that is in accordance with the requirements of physical education and sport, solely with classroom activities. For this reason, extracurricular activities must be given importance, these activities must be considered and valued as a continuation of and an inseparable part of curriculum (Karakücük, 1995). Apart from units and subjects covered in lessons in school, extracurricular sports activities are carried out in a manner that is distanced from a competitive environment and with types of activities that is in accordance with students' knowledge and abilities. The main power of educational practices is student social activities. With such social activities, students gain democratic attitudes as well as knowledge and skills in line with their interests and talents. A huge responsibility falls on physical education teachers here (Gündüz, 1997). It is a well known fact that participation in sport is an effective method in the development of social characteristics during the secondary school period. Individuals' interest in sports activities during the secondary school period can be observed by whether they wish to participate in extracurricular sports activities in the school environment during their free time. For this reason, as much as it is important for secondary school students to be encouraged to do sport and for them to exhibit positive behavior through sport, for them to enjoy sport and ensure they embrace sport as a lifestyle, and the importance of their interest and needs for such activities, solving the problems they face carries just as much significance (Selçuk, 2006). In this respect, this research aims to determine the level of participation of secondary school students in extracurricular sports activities and the issues they experience according to certain variables.

Seeing as people are the most valuable assets of our society, educating them in the best way, developing their skills, kneading them with qualities that are positive in every aspect should also be a mandatory an essential and fundamental duty of society. With a good education, an individual can become a valuable asset to themselves, their families and their nation. The wrong education, however, will result in a value wasted, a life lost (Hergüner, 1992). Physical education must educate a person by physical means. Sports activities have both a learning value within themselves and the value of educating young people with sport (Orhun, 1990). Hence, countries such as Canada and East Germany who have demonstrated success in sports have ensured their current success by establishing their sports systems on school sports with the principle of encouraging everyone to do sport and by raising elite athletes (Açıkada and Ergen, 1990). Education is a series of constant activities implemented to develop and help gain information, behavior and abilities. As an education method, if we also consider sport as a physical and spiritual education, we can accept sport and education as identical concepts (Erkal, 1986). For individuals who do sport, it is a process which results in altering one's behaviors via their own sporting life and which ensures individual and societal change and exchange via athletic activities with the aim of terminal transformations in social life. Sport is an activity assigned to students by schools and which socializes and matures them. Sport can be offered or imposed on students by schools. Along with this, for many children, sport represents wealth in terms of cultural activities, and this is a quality which schools accept and use in accordance with their objectives. And this is a form of social activity (Walker, 1987).

\section{Method}

One of the descriptive models which tries to determine the current situation in this study, the cross-sectional scanning model of the scanning models carried out on large groups was used. In studies which cross-sectional scanning models are used, measurements are taken from the research group at one time and in a momentary fashion (Donmez and Azizoglu, 2010). In this scope, the data collection tool was once and momentarily applied to the secondary school students that comprised the research group, data obtained has constituted the findings of the research. 247 students of the 2016-17 academic year in Burdur's secondary education institutions comprised the study group of the research conducted according to the descriptive scanning model. The students which comprise the study group were selected from Burdur secondary schools with a simple neutral sampling method. In researches which use the simple neutral sampling method, each individual in the universe has an equal chance of being added to the sampling (Can, 2014). The simple neutral sample determining model was used in the selection of the study group for this reason.

A survey composed of a total of 19 questions developed by Selçuk (2006) was used for the collection of research data. Statistical analysis of data collected was conducted with the SPSS22.0 program. Frequency analysis was used to determine the percentage distribution of participants' demographic information. Taking advantage of Custom Tables, a Chi-Square analysis was used for the comparison of the answers participants gave to multiple answer questions in the survey (questions 11, 13,14, 15, 16, 17, 18, and 19) according to their genders. A Chi-Square analysis was applied by using Crosstabs for the comparison of participants' extracurricular sports activities 
according to their gender, grade, professions of their mothers and fathers; the comparison of changes in academic performance as a result of participation in extracurricular sports activities according to grade and gender; and the comparison of family encouragement for engagement in sport according to the profession of parents and the number of people in the family. Level of significance in the Chi-Square analysis has been determined as $\mathrm{p}<0.05$.

\section{Findings}

Table-1. Frequency and Percentage Distribution of Participants According to Their Genders

\begin{tabular}{l|l|l}
\hline Gender & f & \% \\
\hline Female & 127 & 51.4 \\
\hline Male & 120 & 48.6 \\
\hline Total & 247 & 100.0 \\
\hline
\end{tabular}

$51 \%$ of participants are female, whilst $48 \%$ are male.

Table-2. Frequency and Percentage Distribution of Participants According to Which Grade they are in

\begin{tabular}{l|l|l}
\hline Grade & f & \% \\
\hline 10th grade & 91 & 36.8 \\
\hline 11th grade & 83 & 33.6 \\
\hline 12th grade & 39 & 15.8 \\
\hline 9th grade & 34 & 13.8 \\
\hline Total & 247 & 100.0 \\
\hline The highest participation in the study was received by 10th and 11th grade students.
\end{tabular}

Table-3. Frequency and Percentage Distribution of Participants According to the Age they Started Doing Sport

\begin{tabular}{l|l|l}
\hline Age they started doing sport & f & \% \\
\hline ages $7-10$ & 132 & 53.4 \\
\hline ages $11-14$ & 63 & 25.5 \\
\hline ages $3-6$ & 44 & 17.8 \\
\hline ages $15-16$ & 8 & 3.2 \\
\hline Total & 247 & 100.0 \\
\hline More than half of the participants in the study $(53.4 \%)$ started
\end{tabular}

More than half of the participants in the study (53.4\%) started doing sport at ages 7-10.

Table-4. Frequency and Percentage Distribution of Participants According to their Family's Economic Status

\begin{tabular}{l|l|l}
\hline Family's economic status & $\mathbf{f}$ & $\mathbf{\%}$ \\
\hline Mid & 142 & 57.5 \\
\hline Good & 96 & 38.9 \\
\hline Very good & 6 & 2.4 \\
\hline Bad & 2 & 0.8 \\
\hline Very bad & 1 & 0.4 \\
\hline Total & 247 & 100.0 \\
\hline
\end{tabular}

While more than half the participants have families with an average economic status(57.5), an important portion (38.9\%) are from families which have a good economic status.

Table-5. Distribution of Participants with Family Members who Regularly do Sport

\begin{tabular}{l|l|l}
\hline Are there any individuals & f & \% \\
\hline No & 184 & 74.5 \\
\hline Yes & 63 & 25.5 \\
\hline Total & 247 & 100.0 \\
$74.5 \%$ of Participants have an individual at home who regularly does sport.
\end{tabular}

Table-6. Frequency and Percentage Distribution of Participants According to whether their Families Encourage them to do Sport

\begin{tabular}{l|l|l}
\hline Family's encouragement to do sport & $\mathbf{f}$ & \% \\
\hline Supportive & 179 & 72.5 \\
\hline Indifferent & 65 & 26.3 \\
\hline Unsupportive & 3 & 1.2 \\
\hline Total & 247 & 100.0 \\
\hline
\end{tabular}

While $72.5 \%$ of participants are supported by their families to do sport, $1.2 \%$ are not supported. $26.3 \%$ of participants have families who are indifferent.

Table-7. Frequency and Percentage Distribution of Participants According to the Extracurricular Sport Activities they Engage in.

\begin{tabular}{l|l|l}
\hline Sports activities & f & $\%$ \\
\hline Football & 73 & 29.6 \\
\hline Volleyball & 66 & 26.7 \\
\hline Other & 57 & 23.1 \\
\hline Basketball & 25 & 10.1 \\
\hline Athletics & 16 & 6.5 \\
\hline Karate, Judo & 6 & 2.4 \\
\hline Handball & 4 & 1.6 \\
\hline Total & 247 & 100.0 \\
\hline More than half of participants in the study engage in football and volleyball & \\
\hline
\end{tabular}

More than half of participants in the study engage in football and volleyball.

Table-8. Frequency and Percentage Distribution of Participants According to the impact of their Participation in Extracurricular Sports Competitions on their Academic Success

\begin{tabular}{l|l|l}
\hline Impact & f & \% \\
\hline No impact on success & 193 & 78.1 \\
\hline Success increased & 47 & 19 \\
\hline Success decreased & 7 & 2.8 \\
\hline Total & 247 & 100.0 \\
\hline
\end{tabular}

While $78.1 \%$ of participants indicated that their participation in extracurricular sports competitions have not had an impact on their academic success, $19 \%$

have stated their success has increased, and $8 \%$ have stated their success has decreased. 
Table-9. Comparison of the Effects of Extracurricular Sports Competitions on Participants According to their Gender (Multiple Answer)

\begin{tabular}{|c|c|c|c|c|}
\hline Effects & Statistics & Female & Male & Total \\
\hline It improved my self-confidence & f & 62 & 68 & 130 \\
\hline It improved my sense of sharing and helping & $\mathrm{f}$ & 19 & 36 & 55 \\
\hline \multirow{2}{*}{ It helped my social development } & $\mathrm{f}$ & 41 & 51 & 92 \\
\hline & $\%$ & 21.0 & 21.5 & 21.3 \\
\hline It helped my physical and spiritual development & $\mathrm{f}$ & 31 & 38 & 69 \\
\hline It had a positive effect on my academic success & $\%$ & 2.1 & 1.7 & 1.9 \\
\hline \multirow{2}{*}{ It made it easier for me to adhere to social norms } & $\mathrm{f}$ & 3 & 5 & 8 \\
\hline & $\%$ & 1.5 & 2.1 & 1.9 \\
\hline \multirow{2}{*}{ It ensured my spiritual comfort } & $\mathrm{f}$ & 9 & 10 & 19 \\
\hline & $\%$ & 4.6 & 4.2 & 4.4 \\
\hline It improved my leadership skills & $\mathrm{f}$ & 1 & 5 & 6 \\
\hline Other & $\%$ & 5.1 & 5.1 & 5.1 \\
\hline \multirow{2}{*}{ Total } & $\mathrm{f}$ & 117 & 112 & 229 \\
\hline & $\%$ & 100.0 & 100.0 & 100.0 \\
\hline
\end{tabular}

$\mathrm{x}^{2}=19.449 ; \mathrm{df}=10 ; \mathrm{p}=.035$

Statistically, the impact of participation in extracurricular sports events vary significantly according to the gender of participants $(p<0,05)$. While female participants have experienced the effect of an increase in their selfconfidence, male participants demonstrate a higher rate in the development of their sense of sharing and helping.

Table-10. Comparison of Extracurricular Sports Activities According to which Grade Participants are in.

\begin{tabular}{|c|c|c|c|c|c|c|}
\hline Activities & Statistics & 9th grade & 10th grade & 11th grade & 12th grade & Total \\
\hline \multirow{2}{*}{ Athletics } & f & 3 & 3 & 5 & 5 & 16 \\
\hline & $\%$ & 8.8 & 3.3 & 6.0 & 12.8 & 6.5 \\
\hline \multirow{2}{*}{ Football } & $\mathrm{f}$ & 14 & 25 & 25 & 9 & 73 \\
\hline & $\%$ & 41.2 & 27.5 & 30.1 & 23.1 & 29.6 \\
\hline \multirow{2}{*}{ Basketball } & $\mathrm{f}$ & 4 & 8 & 10 & 3 & 25 \\
\hline & $\%$ & 11.8 & 8.8 & 12.0 & 7.7 & 10.1 \\
\hline \multirow{2}{*}{ Handball } & $\mathrm{f}$ & 0 & 1 & 2 & 1 & 4 \\
\hline & $\%$ & 0.0 & 1.1 & 2.4 & 2.6 & 1.6 \\
\hline \multirow{2}{*}{ Volleyball } & $\mathrm{f}$ & 7 & 24 & 25 & 10 & 66 \\
\hline & $\%$ & 20.6 & 26.4 & 30.1 & 25.6 & 26.7 \\
\hline \multirow{2}{*}{ Karate, Judo } & $\mathrm{f}$ & $\mathrm{O}$ & 4 & 1 & 1 & 6 \\
\hline & $\%$ & 0.0 & 4.4 & 1.2 & 2.6 & 2.4 \\
\hline \multirow{2}{*}{ Other } & $\mathrm{f}$ & 6 & 26 & 15 & 10 & 57 \\
\hline & $\%$ & 17.6 & 28.6 & 18.1 & 25.6 & 23.1 \\
\hline \multirow{2}{*}{ Total } & $\mathrm{f}$ & 34 & 91 & 83 & 39 & 247 \\
\hline & $\%$ & 100.0 & 100.0 & 100.0 & 100.0 & 100.0 \\
\hline
\end{tabular}

Statistically, no significant differences have been identified between extracurricular sports activities according to the grade which participants are in $(p>0,05)$.

Table-1 1. Comparison of Extracurricular Sports Activities According to the Gender of Participants

\begin{tabular}{l|l|l|l|l}
\hline Activities & Statistics & Female & Male & Total \\
\hline \multirow{3}{*}{ Athletics } & $\mathrm{f}$ & 6 & 10 & 16 \\
\cline { 2 - 5 } & $\%$ & 4.7 & 8.3 & 6.5 \\
\hline \multirow{3}{*}{ Football } & $\mathrm{f}$ & 5 & 68 & 73 \\
\cline { 2 - 5 } & $\%$ & 3.9 & 56.7 & 29.6 \\
\hline \multirow{3}{*}{ Handball } & $\mathrm{f}$ & 9 & 16 & 25 \\
\cline { 2 - 5 } & $\%$ & 7.1 & 13.3 & 10.1 \\
\hline \multirow{3}{*}{ Volleyball } & $\mathrm{f}$ & 3 & 1 & 4 \\
\cline { 2 - 5 } & $\%$ & 2.4 & 0.8 & 1.6 \\
\hline \multirow{2}{*}{ Karate, Judo } & $\mathrm{f}$ & 60 & 6 & 66 \\
\cline { 2 - 5 } & $\%$ & 47.2 & 5.0 & 26.7 \\
\hline \multirow{2}{*}{ Other } & $\mathrm{f}$ & 3 & 3 & 6 \\
\hline \multirow{2}{*}{ Total } & $\mathrm{f}$ & 2.4 & 2.5 & 2.4 \\
\cline { 2 - 5 } & $\%$ & 41 & 16 & 57 \\
\hline
\end{tabular}

$\mathrm{x}^{2}=113.369 ; \mathrm{df}=6 ; \mathrm{p}=.000$

Statistically, there are significant differences between extracurricular sports activities according to the gender of participants $(\mathrm{p}>0.05)$. While it is mostly football with males, most females participate in volleyball. 


\section{Conclusion}

In conclusion, when taking into account the factor of which grade secondary school students are in, it has been determined that football and volleyball are the most preferred branches of sport, and that there are statistically no significant differences between extracurricular sports activities according to which grade they are in. It has been determined that secondary school students who have participated in the study statistically present no significant differences in their extracurricular sports activities according to the profession of their fathers. It has been determined that the support shown by the families of students participating in the study in terms of their engagement in sports, statistically demonstrates no significant difference according to the number of people in the family. It has been determined that the support shown by the families of students participating in the study in terms of their engagement in sports, statistically demonstrates no significant difference according to the profession of their mothers. It has been observed that the rate of support given for engaging in sport by families of participants whose mothers are white collar workers are higher than other families. It has been determined that the support shown by the families of students participating in the study in terms of their engagement in sports, statistically demonstrates no significant difference according to the profession of their fathers. It has been determined that the support shown by the families of students participating in the study in terms of their engagement in sports, statistically demonstrates no significant difference according to their genders. It has been determined that statistically, there are significant differences between extracurricular sports activities secondary school students engage in, according to their genders. It was found that the changes in academic status during the participation of secondary school students in extracurricular sports competitions statistically demonstrates no significant difference according to their genders. In the instance which there have been changes in academic status due to extracurricular sports competitions, statistically there were no significant differences according to the grade which participants are in. Those whose academic success increased the most were 10th and 11 th grade students. Those who demonstrated no change in success were mostly 9 th and 12 th grade students.

It has been determined that statistically, there are significant differences between the reasons behind which extracurricular sports activities middle school students choose to engage in according to their genders. While males prefer football a lot more, females prefer volleyball. Statistically, there are significant differences in the problems experienced due to participants taking part in extracurricular sports competitions according to their genders. The rate of males who do not experience problems is higher than females. Whilst the issue of school management being reluctant in solving problems is experienced more by males, females experience a lot more problems in terms of attending lessons, issues in academic success and not finding enough time for homework. It has been determined that the problems experienced by middle school students in their education as a result of their participation in extracurricular sports competitions statistically present no significant differences according to which grade they are in. Statistically, there are significant differences in how participants feel on a spiritual level when they do sport according to their genders. Whilst females present a higher rate in feeling happy and feeling better, males present a higher rate in feeling closer and more intimate towards their friends as well as feeling more joyful when they do sport. It has been determined that statistically, there are no significant differences between the views of middle school students regarding how they physically feel when they do sport according to their genders. Statistically, there are significant differences between the people who encourage participants in taking part in extracurricular sports competitions according to their genders. Whilst females present a higher rate in terms of family encouragement, males present a higher rate in the encouragement o PE teachers and friends. It has been determined that statistically, there are no significant differences between the problems experienced my secondary school students within the organization when taking part in extracurricular sports activities according to their genders. This outcome presents discrepancies with the results of Salar (2015). The effect of participation in extracurricular sports organizations statistically present significant differences according to the genders of participants. While female participants have experienced the effect of an increase in their self-confidence, male participants demonstrate a higher rate in the development of their sense of sharing and helping.

1. It has been observed that the participation of secondary school students in extracurricular sports activities have an impact on their educational lives. Necessary adjustments can be made for extracurricular sports activities to be designed in a fashion which will not have an impact on students' educational lives. In this respect, the number of sports activities which students can attend on weekends can be increased.

2. It has been identified that gender is an important determent in the participation of secondary school students in extracurricular sports activities and that there are differences in the extracurricular sports activities preferred by males and females. Likewise, the benefits students gain from extracurricular sports activities present significant differences according to their genders. In this respect, extracurricular sports classes and contests which will attract the interest of both females and males can be organized.

3. It has been determined that there are no significant differences between the problems experienced my secondary school students whilst taking part in extracurricular sports activities according to their genders. Besides this, the opinions of students concerning a more productive execution of extracurricular sports activities present no significant differences according to their genders. For this purpose, it can be considered beneficial for management and administrative bodies of secondary school institutions to carry out studies to determine the needs and expectations of students regarding extracurricular sports activities, to determine the problems experienced by students of both genders and to take certain measures to reduce the issues in question.

\section{References}

Açıkada, C. and E. Ergen, 1990. Science and sports. Ankara: Culture Press.

Binbaşığlu, C., 2000. Extracurricular activities in school. Ankara: MEB Publications.

Can, A., 2014. Data analysis in scientific research process with SPSS. 2nd Edn. Ankara: Pegem Academy.

Cömert, S., 1999. Child health and sports culture. Ankara: Remzi Kitabevi.

Donmez, F. and N. Azizoglu, 2010. Investigation of the students' science process skill levels in vocational schools: A case of Balıkesir. Necatibey Education Faculty Electronic Science and Mathematics Education Journal, 4(2): 79-109. View at Google Scholar

Erkal, M.E., 1986. Sports from sociological perspective. National education Ministry of Youth. B.T.S.G. Directorate publication No: 30. Ankara: National Education Printing House. 
Ertürk, S., 1975. Program development in education. Ankara: Yelkentepe Publications

Gündüz, H., 1997. Teacher and manager opinions on the effectiveness of trainers' work. Graduate Thesis, Hacettepe University Institute of Social Sciences, Ankara.

Hergüner, G., 1992. Education-sports relationship. 19 May University education faculty magazine. Samsun: Eser Press.

Karakücük, S., 1995. Recreation, evaluation of leisure time, concept scope and research. Ankara: Remzi Bookstore.

Orhun, A., 1990. New didactic approaches to school physical education and sports. First National Symposium of Sports Sciences Ankara.

Salar, B., 2015. Levels and problems of secondary education students' participation in extracurricular activities. Mehmet Akif Ersoy University Educational Sciences Institute. Master Thesis. BURDUR

Selçuk, T., 2006. Levels and problems of secondary education students' participation in extracurricular activities. Mersin University, Institute of Health Sciences. Master Thesis. MERSIN

Walker, J.C., 1987. School sport, ethnicity and nationality: Dimensions of male youth culture in an inner-city school. Australian Journal of Education, 31 (3): 303-3 16. View at Google Scholar | View at Publisher 